\title{
La estabilidad de la familia en el Derecho Civil Griego
}

\author{
por D. ZERVOS,
}

\author{
Doctor en Derecho, Abogado, Miembro del Instituto \\ Helénico de Derecho Internacional.
}

\section{DERECHO DE LA FAMILIA Y DERECHO ECLESIASTICO.}

Las disposiciones del derecho familiar son de una importancia capital y primordial para la estabilidad de la familia, pues son ellas que crean y disuelven esa institución, protegida por el orden legal. Por consiguiente, las condiciones que se refieren a la celebración del matrimonio, a sus condiciones, a su disolución, ejercen una influencia decisiva sobre toda la institu. ción de la familia. En la formación general de estas disposiciones un papel capital es desempeñado por los mandamientos de las reglas de la Iglesia Ortodoxa Griega, a la cual pertenece la casi totalidad de los Griegos. En una población griega de cerca de 8 millones, hay aproximadamente 60,000 católicos romanos (que incluyen 1,200 Unitarios y 1,500 Armenios), 120,000 musulmanes, 5,500 israelitas, 15,000 protestantes de diversas sectas (Evangelitas etc.) 10;000 armenios monofisitas, 2,000 estudiantes de Escrituna Sagrada (Chiliastes), perteneciendo los demás a la Iglesia Griega Ortodoxa. Esta influencia de la Iglesia se ha ejercido en el pueblo griego desde la época del Imperio Bizantino -tanto como durante la ocupación turca (14531821),- durante la cual es gracias a la iglesia griega que se han mantenido los usos y costumbres helénicos, el derecho helénico $\mathrm{y}$, en general, se ha conservado durante 400 años la unidad de la nación helénica.

Es así cómo las reglas sagradas de la Iglesia Ortodoxa Griega ya no son para el pueblo helénico simples disposiciones del Derecho Eclesióstico, sino que se han convertido para él en disposiciones del derecho laico costumbristc, una parte intearante de su derecho, independientemente de sus convicciones religiosas. Es así cómo, a pesar de una libertad de conciencia y de convicciones religiosas absoluta, protegida por la constitución, la preponderancia que las disposiciones del derecho costumbrista-eclesiósti- 
co helénico, ha creado, de esta manera, sobre las disposiciones matrimaniales, es evidente.

Condiciones, forma de celebración $\mathbf{y}$ disolución del matrimonio. Bajo la influencia antes mencionada, encontramos en el código civil helénico impedimentos al matrimonio, que son en gran parte desconocidos en Ia mayoría de las legislaciones modernas y que se hallan inspirados en el deseo de evitar matrimonios que, bajo la influencia de las costumbres griegas, no ofrecen garantías para su estabilidad $y$ duración. Así, se prohibe el matrimonio entre un cristiano y una persona de otra religión - pero no entre cristianos de distinto credo (Art. 1355), pues se considera que la total oposición entre los esposos sobre todo lo que se refiere a sus convicciones religiosas $y$, de manera general, el concepto de vida de cada uno de ellos, es contrario a la finalidad del matrimonio y no contribuye a la creación de una institución familiar firme y duradera. Por la misma razón, la celebración de un cuarto matrimonio en Grecia es prohibida, cuando se han realizado tres matrimonios anteriores, contraídos válidamente. No se considera como probable que quien hubiere ya contraído tres matrimonios válidos pueda contraer después uno más estable y de una duración mayor que los anteriores. (C.C. 1355). Como única forma de celebración del matrimonio se ha establecido la ceremonia religiosa (C.C. 1367). El sentimiento religioso, como ya lo hemos expuesto, tiene tan profundas raíces en el corazón del pueblo griego que la ceremonia religiosa celebrada por un sacerdote griego ejerce gran influencia sobre los futuros esposos en cuanto al valor morál del matrimonio civil. Los griegos no ortodoxos celebran su matrimonio según la forma religiosa que prescribe su dogma o su religión (C.C. 1371).

Disałución del matrimonio.-Una influencia decisiva sobre la estabilidad y la duración de la institución familiar es ejercida por las disposiciones que se refieren a la disolución del matrimonio. La fácil obtención del divorcio produce un concepto poco serio del matrimonio, mientras que, por otro lado las dificultades excesivas para la disolución del matrimonio conducen al mantenimiento obligatorio de matrimonios enfermizos, lo que no contribuye a la consolidación del orden moral en la familia y a la estabilidad de la institución familiar, considerada de manera sanx. El legislador griego ha seguido un cambio intermedio. Las disposiciones relativas al divorcio, basadas en principio sobre el quebrantamiento de las relaciones conyugales por culpa de uno de los cónyuges (quebrantamiento subjetivo), no hacen fácil la disolución del matrimonio, pero no lo hacen ni imposible ni demasiado difícil. Debe señalarse que la iglesia griega que, en vista de lo que antecede, ha ejercido una gran influencia sobre la formación de las disposiciones del derecho helénico, ha siempre admitido la disolución del matrimonio por el divorcio. Hoy mismo, cuando se trata de divorcio entre ortodoxos, la iglesia griega interviene activamente. Es así cómo, según el procedimiento civil helénico, antes de la presentación de una demanda de divorcio ante el tribunal, el interesado debe dirigirse por escrito al Obispo del domicilio de los esposos, en vista de una reconciliación. $Y$ es precisamente alebido al profundo sentimiento religioso del pueblo griego quo el esfuerzo 
de la Iglesia se muestra mucho más eficaz y contribuye mucho más al mantenimiento de Ia familia, que cualquier otra autoridad ante la cual se podría presentar dicha demanda. Es así como el gran esfuerzo de conciliación que realiza la Iglesia alcanza en Atenas el $16 \%$ y en el resto del pás el porcentaje es notable si se tiene en cuenta que, cuando se ha presentado la demanda, los esposos se hallan ya virtualmente separados de hecho.

Relaciones personales entre los esposos.-Para la estabilidad de la institución matrimonial y más propiamente dicho de la familia, es indispensable que los esposos lleven una vida común. El art. 1386 del C.C. indica esta obligación así como el derecho de los esposos a vivir en común. Asimismo, aunque la igualdad de los sexos, generalmente admitida, es también reconocida en Grecia, el legislador griego ha creído contribuir $a$, un $\alpha$ vida conyugal normal y a la estabilidad familiar, otorgando al esposo una parte preponderante en la adopción de resoluciones referentes a la vida familiar. De esta manera, pueden adoptarse resoluciones rápidas, princicralmente en los casos críticos de la vida familiar. En todo caso, este derecho preferencial del esposo no es arbitrario, pues la mujer siempre puede dirigirse al tribunal para hacer anular una resolución tomada por su esposo, cuando ésta constituya un abuso del derecho (1387 C.C.) Es también hacia la unidad de la familia que van dirigidas las disposiciones según las cuales la mujer y los hijos rixcidos del matrimonio adquieren el apellido del marido. Las referidas disposiciones que otorgan al esposo esa precedencia con el fin de asegurar la estabilidad familiar se hallan balanceadas, en cierta forma, por las disposiciones del art. 1389 que, con la misma finalidad, es decir para asegurar una vida normal y la estabilidad de la familia, otorga a la mujer la preponderancia para todo lo que se refiera a la administración del "hogar conyugal". De la misma manera, como consecuencia de la disposición del art. 1387 del C.C., para tasegurar la estabilidad de la familia, se indica que el marido es el jefe de la familia, y también se especifica (art. 1391 y sgtes. del C.C.) que es el marido a quien, en primer lugar, corresponde la obligación de mantener a la familia, y que solo cuando él se halla imposibilitado de hacerlo la mujer también debe aportar su contribución.

Relaciones matrimoniales de los esposos. - El matrimonio no dá lugar, en principio, a ningún cambio en la situación, patrimonial de los esposos, pues el Código Civil ha establecido el régimen de la separación de bienes. (1797 C.C.) El legislador griego ha especificado que este régimen es más conforme a la relación moral del matrimonio que el de la comunidad de bienes, aún cuando este parece teóricamente más ventajoso. En efecto, lo que interesa desde el punto de vista moral es la verdadera "fusión" de los patrimonios que se produce después de la celebración del matrimonio y no la "fusión" de los bienes impuesta por la ley. Sin embargo, los esposos griegos se hallan en libertad de estipular por contrato, antes de la celebración del matrimonio, sus relaciones patrimoniales, de acuerdo con su voluntad al margen del sistema de la separación de bienes establecido por la ley. 
Legitimidad de los hijos. - Ejercen una gran influencia sobre la estabilidad de la vida conyugal las disposiciones del art. 1465, del C.C., que plantean el principio de la paternidad, de acuerdo con la regla "pater est quem nuptice demonstrant". Según esta regla, el niño nacido dentro de los ciento ochenta días contados a partir de la fecha de celebración del matrimonio, y dentro de los irescientos días contados desde su disolución o su anulación, se considera hijo legítimo del esposo. Se trata aquí de una presunción legal, que no se considera como absoluta, pues se permite probar lo contrario bajo ciertas condiciones. Sin embargo esta presunción contribuye $a$ la estabilidad de la familia, pues gracias a ella se evitan conflictos conyugales y es únicamente en casos excepcionales, es decir cuando la realidad se encuentra en flagrante contradicción con la presunción, que el esposo se resuelve a negar la paternidad por vía legal y a reconocer al niño.

Obligación alimenticia. - Las disposiciones del Código Civil que se refieren a la obligación alimenticia legal contribuyen también a la estabilidad familiar. Estas disposiciones establecen una noción de obligación alimenticia muy amplia, para los parientes - late sensu- que no se hállan en condiciones de subvenir a sus necesidades (art. 1477). Así se observa en el Código Civil, además de la obligación alimenticia entre descendientes y ascendientes, una obligación alimenticia entre hermanos $\mathrm{y}$ hermanas (art. 1492). Por esta disposición el legislador griego ha tratado de mantener el lazo que une a hermanos y hermanas que no pertenecen tal vez hoy $\alpha$ la misma familia, pero que han nacido $y$ se han educado bajo el mismo techo familiar.

Relaciones entre padres e hijos.-Para el mantenimiento de la estabilidad $y$ de la unidad familiar, se establece (art. 1493) que el hijo recibe el c.pellido de su padre. Asimismo, el art. 1494 establece que el hijo debe prestar a su familia todos los servicios necescrios que le sea posible prestar. El Código Civil griego, teniendo en cuenta que el padre debe tener la precedencia, específica que el padre ejerce la patria potestad sobre el hijo menor de edad. La patria potestad se halla estrechamente ligada a la persona del padre. Si se produce un divorcio entre los esposos, es posible que los cuidados y la educación de los hijos sean entregados a la madre, pero la patria potes'ad es siempre del padre. Si muere el padre o es privado de la patria potestad, ésta concluye y es reemplazada por la tutela. Excepcicnalmente y en caso de impedimento, la madre ejerce la patria potestad, pero no por derecho propio, sino a nombre del padre (1500, par. II, C.C.). Cuando cesa la patria potestad, el menor se halla bajo tutela. Según el art. 1590, C.C., la madre es la primera lhamada ya asumir la tutela del hijo. Pero no se considera que se contribuye a la estabilidad de la familia, manteniendo la tutela cuando la madre contrae nuevo matrimonio; es por esto que, en tal caso, la tutela de la madre deja de ser obligatoria, para convertirse en facultativa (1595-1597, C.M.). También se refiere a la estabilidad farmiliar el art. 1619 según el cual el consejo de formilia, es decir el consejo 
que vigila la gestión del tutor, está constituído por los seis parientes más cercanos del menor, en número igual de las ramas paterna y materna.

Tutela. - El legislador griego, partiendo de la opinión según la cual el sometimiento del menor casado a la-patria potestad no es conforme al matrimonio y a su estabilidad, declara emancipado al menor después de la celebración del matrimonio. El esposu menor emancipado se halla colocado bajo la curatela del padre y, fallecido éste, la madre asume esta función. Pero, la menor huérfana de padre estó colocada bajo la curatela de su esposo. Estas disposiciones se consideran como debiendo contribuir mejor $\alpha$ la consolidación y a la estabilidad de la nueva familia.

Hijos naturales. - Una gran influencia sobre la estabilidad de lus tamilias actuales y futuras es ejerciad sin auda por las alsposiciones que se refieren a los hijos naturales. En este caso, el legislador duda entre los sentimientos humanos y la oportunidad y la defensa de la familia legitima. Los primeros exigen que el hijo natural sea considerado igual al hijo legítimo, pues el hijo no es responsable por no haber nacido de manera legítima y no es permitido colocarlo en situación inferior por un hecho del que no es responsable. Sin embargo, por una parte la Iglesia siendo contraria a las uniones ilegítimas, $Y$ por otra parte el Estado en su interés de proteger las uniones legítimas de sus súbditos, exigen que el hijo natural no sea completamente igual al hijo legítimo, pues tal igualdad solo perjudicaría a la familia legítima o, por lo menos, presentaría un obstáculo a la formación de tal familia. Por estos motivos, el Código ha adoptado una solución intermedia. Establece dos instituciones: la del reconocimiento y la de la legitimación. En caso de reconocimiento (arts. 1533-1540), la ley protege a los hijos dándoles diversos derechos con relación a su padre, derechos que son más numerosos en caso de reconocimiento voluntario (1537 C.C.) y menos numerosos en caso de reconocimiento judicial (1545 C.C.) La legitimación que convierte al hijo natural en igual al hijo legítimo se obtiene, en principio, por el matrimonio subsiguiente de los padres (1566 C.C.). De esta manera, el legislador trata de convertir en legítima la unión de los padres $y$ de arreglar la situación. Además de la legitimación por matrimonio de los padres, existe la legitimación por sentencia judicial. Sin embargo, una sentencia judicial, aún cuando convierte al hijo natural en legítimo, se presenta como una excepción y solo puede realizarse cuando, por fallecimiento o por algún otro motivo, la legitimación por subsiguiente matrimonio de los padres resulta imposible $y$ siempre que el padre no tuviere descendientes legítimos (1561 C.C.) Además si el hijo mencionado es casado, su esposa debe consentir también a la leqitimación por escritura pública (1562 C.C.) Por fin, el reconocimiento del hijo natural y la atribución que se le hace de todos los derechos de un hijo legítimo también se verifica en caso de reconocimiento judicial: éste se realiza cuando la concepción del niño se ha verificado brajo las condiciones excepcionales que menciona la ley (1555 C.C.) 
Adopción. - La unidad y la estabilidad de la familia también han sido tomadas en cuenta al instituirse la adopción, reconocida por la ley. según la cual hijos pueden ser adoptados por familias sin descendencia. El único beneficiado con la adopción debe ser el adoptado quien, a partir de lia adopción, ocupa con relación al adoptante el rango de un hijo legítimo, mientras que el adoptante no posee ningún derecho a la sucesión del hijo adoptivo (1579 C.C.) Para lograr este fin, se especifica que la autorización de adoptar a una persona como hijo solo se concede cuando el solicitante no tiene descendientes legítimos, $y$ siempre que tenga cincuenta años cumplidos; $\alpha$ esta edad no es probable que llegue a tener descendientes legítimos y de esta manera la situación del hijo adoptivo queda mejor asegurado (1568 C.C.).

También se precisa que los padres no pueden adoptar a su hijo natural, pues si lo desean, tienen otros medios para darle la categoría de hijo legítimo, (art. 1569 C.C.). También se establece que el adoptante no puede adoptar a más de un hijo la no ser que esta adopción se efectúe en un mismo documento (1570 C.C.); que el mismo hijo no puede ser adoptado por más de una persona (1572 C.Cñ. y rue el tutor no puede adoptar al menor que se halla bajo su tutela (1571 C.C.) El adoptonte debe tener cuendo menos dieciocho años más que el adoptado (1574 C.C.), y si es casado, debe obtener el consentimiento de su cónyuge que puede, también, adoptar al mismo hijo - caso único de adopción de una misma persona por varias otras- (1573 y 1572 C.C.). La adopción termina si se establece que, por mala conducta, su mantenimiento es injustificado (1587 C.C.) y principalmente en caso de matrimonio entre el adoptante $\mathrm{v}$ el adoptado, contraído después de la adopción, en violación de la ley.

Interdicción, Consejo Judicial, Tutela del menor.-Las disposiciones relativas a estos capítulos también toman en cuenta la estabilidad familiar, pues, de acuerdo con ellas, quien, por causa de enfermedad o de ausencia, no puede administrar su patrimonio se halla sometido a la tutela de sus padres a pedido de éstos (1688 C.C.). Es así cómo los miembros de una familia se convierten, mediante dichas disposiciones, en protectores de sus miembros que requieren ayuda.

PRINCIPIOS GENERALES, DERECHO DE LASS OBLIGACIONES, DERECHO DE SUCESIONES. - Entre las disposiciones del derecho civil que ejercen influencia sobre la familia y su estabilidad y que pertenecen a romas distintas del Derecho Familiar, podemos mencionar las siguientes:

a)-Principios generales. - Las disposiciones de los artículos 55 y 56 del C.C. se refieren al domicilio y según ellas la mujer casada y los menores emancipados tienen como domicilio el del esposo o padre. También contribuye a la estabilidad de la familia la disposición del art. 1445 del C.C., según la cual el hecho de que uno de los esposos es declarado ausente no produce automáticamente, la disolución del matrimonio, pero constiinye una causal de divorcio. Es, por fin, a la estabilidad y al respeto del 
honor familiar que contribuye, entre las disposiciones de los principios generales, la disposición del artículo 57, según la cual el cónyuge, los ascendientes, los descendientes, los hermanos y hermanas tienen el derecho de exigir la supresión de cualquier atentado contra el buen nombre o la personalidad de un difunto. Es al mismo fin que contribuyen Ias disposiciones de los artículos 365 y 368 del Código Penal según las cuales la esposa. y los hijos del difunto y- si no existen - los padres, los hermanos y las hermanas tienen el derecho de exigir legalmente el castigo de quien ha atentado de manera ilícita contra la memoria del difunto.

b)-Derecho de I,as Obligaciones. - Según las disposiciones del "moratorium" vigente, se puede mencionar como favoreciendo la institución matrimonial y contribuyendo a su estábilidad: 1) las disposiciones del Capítulo IV (art. 18 ss.), según las cuales la prórroga obligatoria del contrato de locación y el derecho al mantenimiento en el lugar son reconocidos, después de la muexte del arrendatario, a hiovor de todos los parientes más cercanos de éste, que cohabitaban con él en el instante de su muerte. - (2)-las disposiciones del art. 25, según las cuales la cohabitación de los miembros de la familia del arrendatario no constituye un subarriendo y es siempre autorizada. Dichas disposiciones son de gran importancia principalmente en una época de relativas dificultades de alojamiento. Por fin, la celebración de nuevos matrimonios se facilita por las disposiciones del artículo 34, según las cuales la casa ocupada puede ser reocupada por su propietario si ia constituye en dote como hogar para una nueva familia que va a constituirse.

c).-Derecho de sucesiones. - 1) Las disposiciones de los artículos 1817 y siguientes establecen el derecho sucesorio ab intestat de los herederos del difunto. El art. C.C., estableciendo especialmente el derecho hereditario ab intestat del cónyuge sobreviviente, dispone que éste hereda si se halla en concurrencia con herederos que no sean los descendientes; recibe, como anticipo de herencia los muebles, utensilios, ropa y otros objetos del menaje que utilizaban ya sea uno de los cónyuges o los esposos conjuntamente. Esta disposición contribuye a mantener el recuerdo de la vida familiar, aún después del fallecimiento de uno de los esposos.- 2) A la estabilidad de la familia y a la vida armoniosa de la familia en general contribuyen también las disposiciones que se refieren a la partición (artículos 1891-1894 del C.C.). De acuerdo con estas disposiciones, el ascendiente, con la condición de que sus actuales descendientes serón sus herederos a su muerte, con el fin de evitarles conflictos fraternos eventuales en cuanto a la división de los bienes de la herencia o deserando repartir su patrimonio entre sus hijos según sus inclinaciones y la aptitud dè cada uno, puede proceder durante su vida a la partición de su pátrimonio entre sus descendientes.- 3) También se puede considerar las disposiciones del artículo 1825 del Código Civil, según las cuales una reserva legal en la sucesión es otorgada al cónyuge superstite y a los descendientes. Este derecho, sin embargo, se basa en el lazo moral eștrecho que procede de 
las relaciones familiares entre el testador $y$ sus herederos. Por consiguiente, euando dicho lazo ha experimentacio un serio gólpe como consecuencia de una de los motivos mencionados en el artículo 1839 y siguientes del C. C., la base moral del derecho ya no existe y sería poco conforme con la estabilidad de la familia el desear mantenerla. Es por esta razón que se reserva al testador la posibilidad de desheredar al descendiente $\longrightarrow$ pariente en general - indigno. Por consiguietne, dichas disposiciones también contribuyen a la estabilidad y a la paz familiar, ya que alejan a los miembros de una familia de toda lacción desfavorable a esta institución. -4)El artículo 1895 del Código Civil establece la obligación entre los descendientes de colacionar, en el acto de la partición, alguna categoría de bienes. El legislador ha partido del punto de vista según el cual el padre $y$ la madre tienen en principio el mismo afecto para todos sus hijos y que esta disposición legal contribuye sin duda alguna a la estabilidad de la familia y a la paz familiar. 5) Por fin, los artículos 1929 y 1930 del Código Civil establecen el fideicomicio formiliar, el que se limita, sin embargo, a un solo grado, por su carácter anti-económico.

NOTA:-Este capítulo es porte del informe presentado sobre la "Estabilidad de la familia en el Derecho Helénico". por el Instituto Helénico de Derecho Internacional al Primer Con. greso Intermacional de Derecho Comparado de la Asociación Internacional de Ciencias Jurídicas (Barcelona, 1956), al que concurrió el Sr. Dr. Félix Navarro Irvine, entances Presidentē del Consorcio de Abogados Católicos de Lima, y actual miembro de su Consejo Directivo.-- Nos tha parecido interesante publicar este trabajo, traducido del francés, pues contiene informaciones sobre el Derecho Griego, poco conocido entre nosotros. 